Research Article

\title{
Large-Scale Shaking Table Test of Seismic Response Laws for a Shallow Double-Arch Tunnel under Unsymmetrical Pressure with a Damping Layer
}

\author{
Hui Yang $\mathbb{D}^{\mathbb{D}}$, Wang Zhou $\left(\mathbb{D}\right.$, Chan Liu $\mathbb{D}^{\mathbb{D}}$, Xueliang Jiang $\mathbb{D}$, and Lei Yu $\mathbb{D}$ \\ Civil Engineering College, Central South University of Forestry and Technology, Changsha 410004, China \\ Correspondence should be addressed to Wang Zhou; 793539691@qq.com
}

Received 10 July 2020; Revised 30 July 2020; Accepted 8 August 2020; Published 26 August 2020

Academic Editor: Hang Lin

Copyright (c) 2020 Hui Yang et al. This is an open access article distributed under the Creative Commons Attribution License, which permits unrestricted use, distribution, and reproduction in any medium, provided the original work is properly cited.

\begin{abstract}
Based on the similarity theory, a large-scale shaking table test of a shallow double-arch tunnel under unsymmetrical pressure with a similarity ratio of $1: 20$ was designed and completed, and a foam concrete damping layer was set in the double-arch tunnel. The acceleration response, strain response, and crack distribution of double-arch tunnels under different intensities and different directions of the Wenchuan wave excitation were studied (WC-X, WC-Z, and WC-XZ). The results showed that (1) the bias side (right hole) is greatly affected by the unevenness of the cover soil, and the horizontal acceleration response difference between the two tunnels is large and there is no symmetry. The incident direction of seismic waves has a great influence on the acceleration response of double-arch tunnels. The amplification factor of WC-Z is greater than that of WC-X. (2) On the same horizontal plane, with the vertical centerline of the middle wall as the axis of symmetry, the vertical acceleration amplification factor also has a large difference between the arch foot and the shoulder, but the difference is relatively small at other points. (3) The dynamic strain increases with the increase of seismic intensity, and the tendency is similar under the three different seismic wave excitation directions. The lining is under tensile strain and compressive strain, the strain of the left hole is greater than the strain of the right hole, and severe stress concentration occurs at the top left of the mid partition. (4) The middle partition, shoulder, and vault of the left hole and the shoulder, vault, and foot of the right hole are weak parts of earthquake resistance. Therefore, special attention should be paid to the seismic design.
\end{abstract}

\section{Introduction}

In recent years, tunnel engineering has developed from small spans and small spaces to large spans and large spaces, and the types of structures have become more complicated. Coupled with the limitations of terrain and other conditions, more and more double-arch tunnels have appeared. The double-arch tunnels are widely used because of their advantages of high space utilization, smooth linearity, and good integrity. However, double-arch tunnels are more prone to damage than ordinary tunnels due to problems such as complex cross-sectional shapes and large spans. Nearly $80 \%$ of China's land area is in an antiseismic zone above 6 degrees, making it an earthquake-prone country. Therefore, studying the dynamic response characteristics of double-arch tunnels during earthquakes has become a problem that must be faced in current engineering construction.

At present, many scholars have used numerical simulation methods to study the dynamic response of doublearch tunnels. Through the numerical analysis of the finite element model, the weakest part of the seismic performance of the double-arch tunnel was obtained [1]. Yang [2] studied the variation and distribution characteristics of the stress field, displacement field, and plastic zone of the double-arch tunnel through numerical simulation. Ling [3] found that the invert, arch foot and spandrel of the double-arch tunnel are the weak link of earthquake resistance through numerical analysis. Yang et al. [4] used numerical calculations to find that the response of the middle wall in the doublearch tunnel to the seismic response is much larger than that in the single tunnel with the same span and depth under the 
same intensity. Wang et al. [5] used three-dimensional numerical simulation to conclude that the middle of the invert and middle wall of the double-arch tunnel are the seismic weak points.

Although numerical simulation can simplify complex engineering problems, the reliability of numerical simulation depends on whether the mechanical parameters and boundary conditions of the model meet the actual conditions, so its limitations are greater. The shaking table test can directly and effectively reproduce the failure mechanism and failure mode of the structure under earthquake action. There are many literatures in which scholars have used the shaking table test to study the antiseismic characteristic and shock absorption of tunnel structures [6, 7]. Jiang et al. [8,9] and Wang et al. [10] studied the acceleration and dynamic strain response of a shallow burial biased small clearance tunnel lining by the shaking table test. Zhenchang et al. [11] studied the seismic dynamic response of large section tunnel under shallow cover and unsymmetrical loading through the shaking table test and found out the influencing factors of the dynamic stress peak and the crack development characteristics of the lining structure. Shuaishuai et al. [12] analyzed the dynamic response and failure characteristics of the lining under different excitation directions through the shaking table test. Wang et al. [13] studied the seismic damage mechanism and damping technology of tunnels at the junction of soft and hard rock in high-intensity areas through the shaking table test. Ping et al. $[14,15]$ concluded that the installation of the damping layer can reduce the internal force peak of the lining under the earthquake load and improve the seismic performance of the single-hole tunnel through the shaking table test. Hajialilue-Bonab et al. [16] studied the dynamic response of a circular tunnel under the sinusoidal excitation and the influence of related parameters on the tunnel through a shaking table test. In addition, there are many international literatures that use the shaking table test to study the dynamic response of underground structures $[17,18]$.

According to the research status of seismic resistance and shock absorption of double-arch tunnels, based on the effective method of shaking table test, the author uses the foam concrete damping layer to reduce the dynamic response of the tunnel. Also, a physical model of the doublearch tunnel with a geometric similarity ratio of $1: 20$ was designed and fabricated, and the shaking table test was carried out. The acceleration and strain response of the shallow double-arch tunnel under unsymmetrical pressure are studied when different seismic wave excitation intensities and different excitation directions are input. The research results can provide a useful reference for the seismic design of double-arch tunnels.

\section{Shanking Table Test}

2.1. Test Equipment. The test was completed in the Laboratory for High-Speed Railway Construction Technology of Central South University. The main parameters of the vibrating table are shown in Table 1, and Figure 1 shows the shaking table device.
2.2. Similarity Relation. The experiment uses a gravity distortion model based on the similarity theory [19, 20]. After considering the parameters of the shaking table and the material factors, the geometric, acceleration, and density similarities of the physical model are determined. The remaining major similarity constants were derived according to the similarity theory, and the similarity constants are shown in Table 2.

2.3. Model Box and Boundary Conditions. The rigid model box used in the test is shown in Figure 2 $(3.5 \mathrm{~m} \times 1.5 \mathrm{~m} \times 2.1 \mathrm{~m}$, length $\times$ width $\times$ height $)$. In order to make the test rock layer better reproduce the seismic response of the free field, the interior of the model box is designed as follows [21, 22]:

(1) A layer of fine stone was laid on the bottom of the model box, a layer of fine sand was laid on the fine stone, and a layer of cement mortar was cast to form a friction boundary

(2) The $10 \mathrm{~cm}$ thick foam board of the inner side wall of the model box is processed into a flexible boundary, and the smooth film is adhered to form a sliding boundary

2.4. Test Materials. The coarse aggregate in the lining was simulated with medium coarse sand. The double-layered steel bars of the lining were simulated using a doublegalvanized wire mesh. After many tests, the average compressive strength of the $100 \mathrm{~mm}$ cube test piece of microconcrete is $2.5 \mathrm{MPa}$, and the weight ratio of the material is $1: 7.83: 1.64$ (cement: sand: water). The thickness of the vault is $3 \mathrm{~cm}$, the thickness of the invert arch is $2 \mathrm{~cm}$, and the thickness of the foam concrete damping layer is $1 \mathrm{~cm}$. The compressive strength of the foamed concrete is $0.5 \mathrm{MPa}$. The ratio of foam concrete is foam: $0.91 \mathrm{~m}^{3}$, cement: $256.8 \mathrm{~kg} / \mathrm{m}^{3}$, fly ash: $171.2 \mathrm{~kg} / \mathrm{m}^{3}$, water: $214 \mathrm{~kg} / \mathrm{m}^{3}$, and glass fiber: $1 \mathrm{~kg} / \mathrm{m}^{3}$. Figure $3(\mathrm{a})$ shows the foam material used for foam concrete, and Figure 3(b) shows its uniaxial compression test. Material parameters are shown in Table 3.

2.5. Lining and Surrounding Rock. The lining was cured for 7 days after pouring, and the outer surface was coated with $1 \mathrm{~cm}$ thick foam concrete and cured until the strength was completely formed. The lining model is shown in Figure 4. The upper layer is a $\mathrm{V}$ class surrounding rock with a thickness of $1 \mathrm{~m}$, which is simulated by silty clay. The lower layer is a IV class surrounding rock with a thickness of $0.48 \mathrm{~m}$, which is prepared from barite powder, quartz sand, and lithium-based grease and has a weight ratio of $10: 5: 1$. When burying the surrounding rock, the integrity of the surrounding rock should be maintained to avoid faults and discontinuities in the surrounding rock, which will cause shear failure and affect the lining [23-25]. The surrounding rock dimensions are shown in Figure 5. 
TABLE 1: Parameters of the shaking table.

\begin{tabular}{lcc}
\hline Table size & \multicolumn{2}{c}{$4.0 \mathrm{~m} \times 4.0 \mathrm{~m}$} \\
Maximum load & $30 t$ \\
Working frequency & $0.1-50 \mathrm{~Hz}$ \\
Maximum displacement & $X$ - and Y-direction & $250 \mathrm{~mm}$ \\
& Z-direction & $160 \mathrm{~mm}$ \\
Maximum acceleration & $X$ - and $Y$-direction & $\pm 1.0 \mathrm{~g}$ \\
& $X$ - and $Y$-direction & $\pm 1.6 \mathrm{~g}$ \\
\hline
\end{tabular}

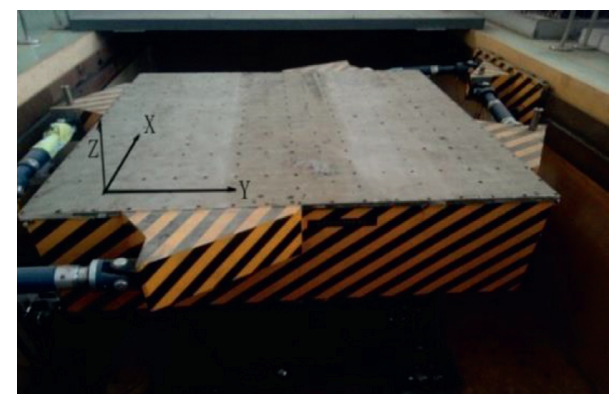

Figure 1: Shaking table.

TABLE 2: The main similarity constants of the model to prototype.

\begin{tabular}{lcc}
\hline Physical quantity & Similar relation & Similar constants \\
\hline$L(\mathrm{~m})$ & $C_{l}$ & 20 \\
$\rho\left(\mathrm{kg} \cdot \mathrm{m}^{-3}\right)$ & $C_{\rho}=1$ & 1 \\
$E(\mathrm{MPa})$ & $C_{E}=C_{\rho} \cdot C_{l}$ & 20 \\
$\varepsilon$ & $C_{\varepsilon}=1$ & 1 \\
$\sigma(\mathrm{kPa})$ & $C_{\sigma}=C_{\rho} \cdot C_{l}$ & 20 \\
$M$ & $C_{\mu}=1$ & 1 \\
$T(\mathrm{~s})$ & $C_{t}=C_{l}^{0.5}$ & 4.47 \\
$A\left(\mathrm{~m} \cdot \mathrm{s}^{-2}\right)$ & $C_{a}=1$ & 1 \\
$U(\mathrm{~mm})$ & $C_{u}=C_{l}$ & 20 \\
$v\left(\mathrm{~mm} \cdot \mathrm{s}^{-1}\right)$ & $C_{v}=C_{l}^{0.5}$ & 4.47 \\
$\omega(\mathrm{Hz})$ & $C_{w}=C_{1}^{-0.5}$ & 0.224 \\
$\varphi\left({ }^{\circ}\right)$ & $C_{\varphi}=1$ & 1 \\
$\gamma\left(\mathrm{kN} \cdot \mathrm{m}^{-3}\right)$ & $C_{\gamma}=C_{\rho}$ & 1 \\
$C\left(\mathrm{kN} \cdot \mathrm{m}^{-2}\right)$ & $C_{c}=C_{\rho} \cdot C_{l}$ & 20 \\
\hline
\end{tabular}

${ }^{*} L$ : length, $\rho$; density, $E$ : elastic modulus, $\varepsilon$ : strain, $\sigma$ : stress, $\mu$ : Poisson ratio, $T$ : time, $a$ : acceleration, $u$ : displacement, $v$ : velocity, $\omega$ : frequency, $\varphi$ : internal friction angle, $\gamma$ : specific weight, $C$ : cohesion.

2.6. Layout of Sensors. The main types of data collected in the test were the acceleration and strain of the lining. The instruments used are one-way acceleration sensors (model: 1221L-002, number: A1 to A12) and resistance strain gauges (model: BX120-50AA, number: S1 to S16). The acceleration measuring point arrangement is shown in Figure 5, and the strain measuring point arrangement is shown in Figure 6.

2.7. Seismic Wave Loading Scheme. Wenchuan wave is used as the input seismic wave, and the loading direction is shown in Figure 5 (WC-X (horizontal), WC-Z (vertical), and WC$\mathrm{XZ}$ (horizontal and vertical)). The acceleration time history curve and the Fourier spectrum of Wenchuan wave are shown in Figures 7 and 8. Before the start of the test at all levels, the white noise previbration was performed for $60 \mathrm{~s}$. The loading scheme is shown in Table 4.

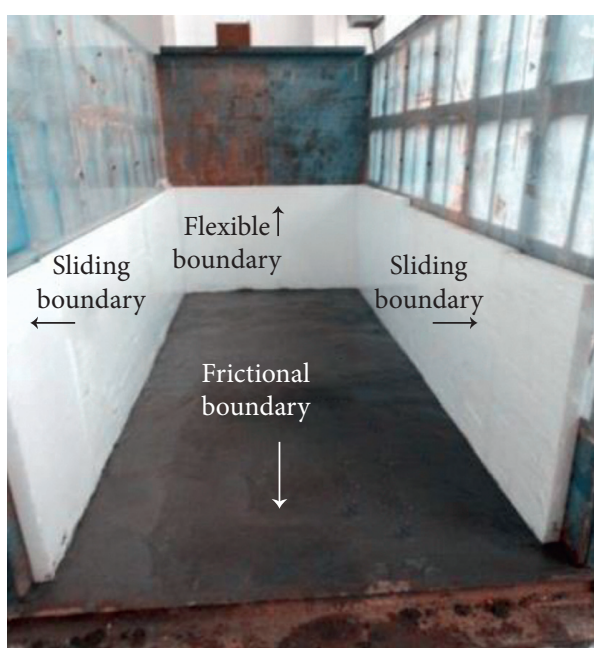

Figure 2: Model boundary.

\section{Analysis of Test Results}

3.1. Analysis of the Acceleration Response of the Double-Arch Tunnel Lining. When analyzing acceleration data, the acceleration amplification factor (AAF) is used to describe the acceleration response law of the model. The rules are as follows: Based on the acceleration of the vibration table, the horizontal $X$-direction amplification factor is the ratio of the horizontal peak acceleration of the measurement point to the horizontal peak acceleration of the vibration table. The vertical $Z$-direction amplification factor is the ratio of the vertical peak acceleration of the measuring point to the vertical peak acceleration of the vibration table.

\subsubsection{Acceleration Response Law under Different Loading Directions}

(1) The Law of Horizontal Acceleration Response. As shown in Figure 9, in the WC-X excitation, the trendency of the left hole acceleration amplification factor exhibits an M-shape (A2 to A6). The AAF of spandrel (A3) and the top of the middle wall (A5) are the two maximum points of the $\mathrm{M}$-shape, and the AAF of spandrels is slightly larger than the top of the middle wall. The AAF of the vault (A4) is the minimum point of the $\mathrm{M}$-shape and the minimum point of the horizontal acceleration amplification factor of the left hole. There is no symmetry in the trendency of the right and left hole acceleration amplification factor, which indicates that the unevenness of the soil cover has a great influence on the symmetry of the acceleration response of the right hole.

The maximum acceleration amplification factor of the double-arch tunnel is 1.86 at the left hole spandrel (A3), the minimum value is 0.55 at the right hole arch foot (A11), and the difference between the other points is larger. This shows that the horizontal acceleration amplification factor of the double-arch tunnel is related to the position of the measuring point. On the same level, with the vertical centerline of the partition wall of the double-arch tunnel as the axis of symmetry, the difference between the left and right 


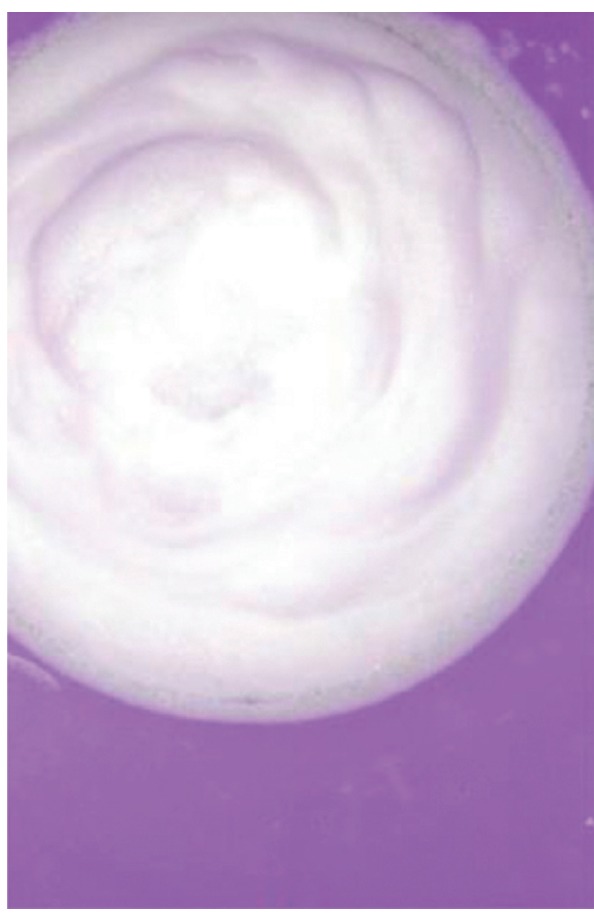

(a)

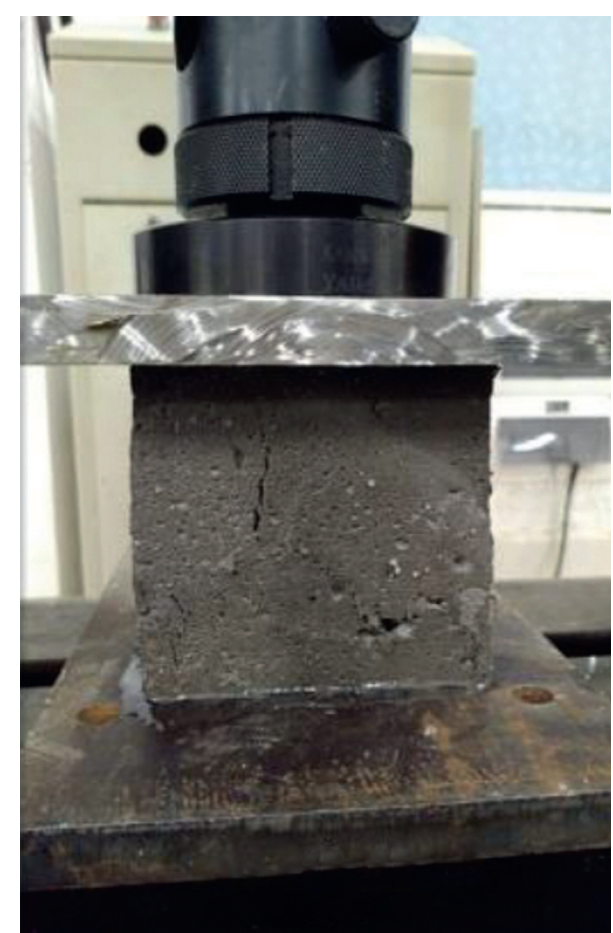

(b)

FIgURE 3: Uniaxial compression test of foam concrete.

TABLE 3: Rock and lining material parameters.

\begin{tabular}{lccccc}
\hline Materials & $E(\mathrm{MPa})$ & $\mu$ & $\varphi\left(^{\circ}\right)$ & $C(\mathrm{kPa})$ & $\gamma\left(\mathrm{kN} \cdot \mathrm{m}^{-3}\right)$ \\
\hline V CSR & 650 & 0.40 & 26 & 120 & 19 \\
IV CSR & 9450 & 0.33 & 35 & 560 & 19 \\
Lining & 17250 & 0.2 & - & - & 24 \\
\hline
\end{tabular}

${ }^{*} E$ : elastic modulus, $\mu$ : Poisson ratio, $\varphi$ : internal friction angle, $C$ : cohesion, $\gamma$ : bulk density, V CSR: V class surrounding rock.

symmetrical points is obvious. Such as, (1) the response of the top left of the mid partition (A5) is much larger than that of the top right of the mid partition (A8). (2) The AAF of the vault of the left hole (A4) is much smaller than that of the vault of the right hole (A9). (3) The acceleration response of the spandrel of the left hole (A3) is greater than that of the spandrel of the right hole (A10) at $0.1 \mathrm{~g}$ and $0.2 \mathrm{~g}$ and smaller than that of the spandrel of the right hole (A10) at $0.4 \mathrm{~g}$ and $0.6 \mathrm{~g}$. (4) The AAF of the invert (A1) and arch foot (A2) of the left hole are much larger than the invert (A12) and the arch foot (A11) of the right hole. Reasons for the asymmetry of the left and right measuring points: First, the unevenness of the slope covering soil leads to a large difference in seismic inertial force between the symmetrical points. Second, the slope generates a superimposed wave field, which has an amplification effect on the acceleration response value of the measuring point near the slope.

As shown in Figure 10, in the case of the WC-XZ excitation, the overall trend of the horizontal acceleration amplification factor of the left hole is similar to that of the WC-X excitation, showing the shape of M (A2 to A6), and the acceleration amplification factor is greater than $0.4 \mathrm{~g}$ and
$0.6 \mathrm{~g}$ at $0.1 \mathrm{~g}$ and $0.2 \mathrm{~g}$. The difference is that the difference between the amplification factors of the two maximum points (A3 and A5) of the curve line $M$ is reduced under the bidirectional action. At the vault (A9), the spandrel (A10), and the arch foot (A11), the trendency of the horizontal acceleration amplification factor of the right hole differs greatly from that of the WC-X. Comparing with Figure 11, it can be seen that the difference is due to the fact that the acceleration amplification factor of the vault and the arch foot is much larger than the WC-X excitation when excited by WC-XZ.

In Figure 11, the difference between WC-XZ and WC-X is positive or negative, indicating that, after the vertical wave participates in the excitation, increasing or decreasing the horizontal acceleration amplification factor is related to the position of the measuring point. For example, at $0.4 \mathrm{~g}$, the right hole arch foot (A11) is increased by $84.5 \%$, and the right hole vault (A10) is reduced by $20.8 \%$. According to the theory of elastic wave scattering, the wave field splitting occurs when horizontal and vertical seismic waves encounter tunnels, and reflection and refraction occur on the lining surface. The measured points in the superimposed area show enhancement, and the measured points in the weakened area show a decrease.

(2) The Law of Vertical Acceleration Response. As shown in Figure 12, when WC- $Z$ is excited, the vertical acceleration amplification factor of the double-arch tunnel is the largest in the middle wall. The acceleration amplification factor continues to decrease toward both sides, the left hole rises after passing through the minimum point spandrel (A3), and 


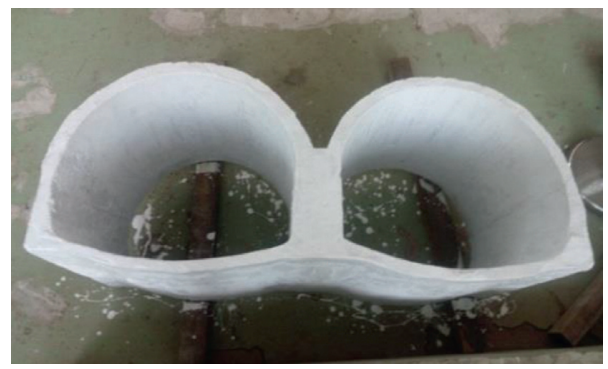

FIgURE 4: Lining model.

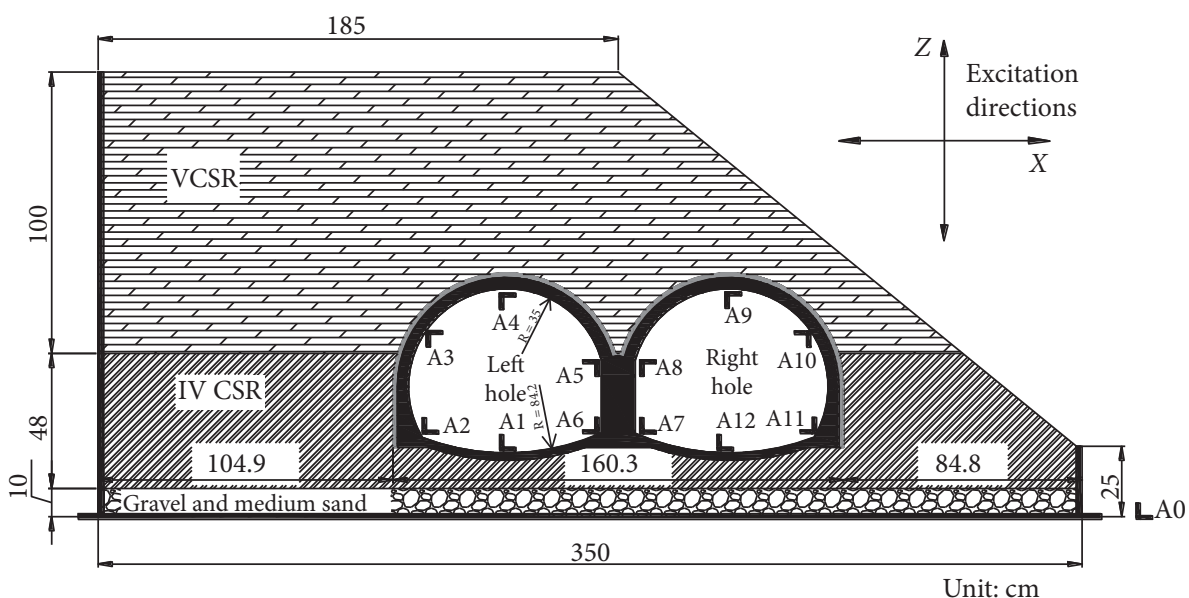

L Accelerometer

FIGURE 5: Layout scheme of the accelerometer.

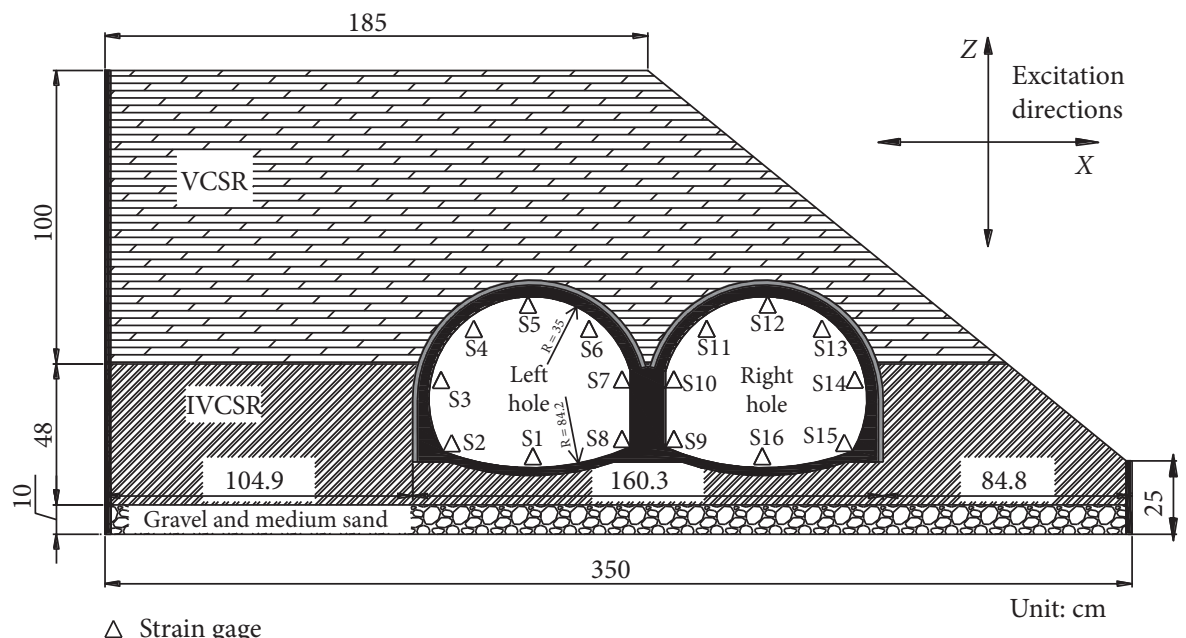

FIgURE 6: Layout scheme of the strain gage.

the right hole rises after passing through the minimum point arch foot (A11). Except the amplification factor of A3 and A11 which is less than 1, all other points have an amplification factor greater than 1 . For example, the values of the measuring points on the middle wall are between 1.5 and 3.5, indicating that the vertical acceleration of the middle wall exhibits a significant amplification effect under the excitation of vertical seismic waves. The reason why the middle wall responds strongly is that the gravity of the upper part of the double-arch tunnel is concentrated on the middle wall, and the mid wall is subject to larger earthquake inertia. The cross-sectional geometry of the top and bottom of the middle wall is abruptly changed, resulting in concentrated forces.

On the same level, with the vertical centerline of the double-arch tunnel as the axis of symmetry, the difference 


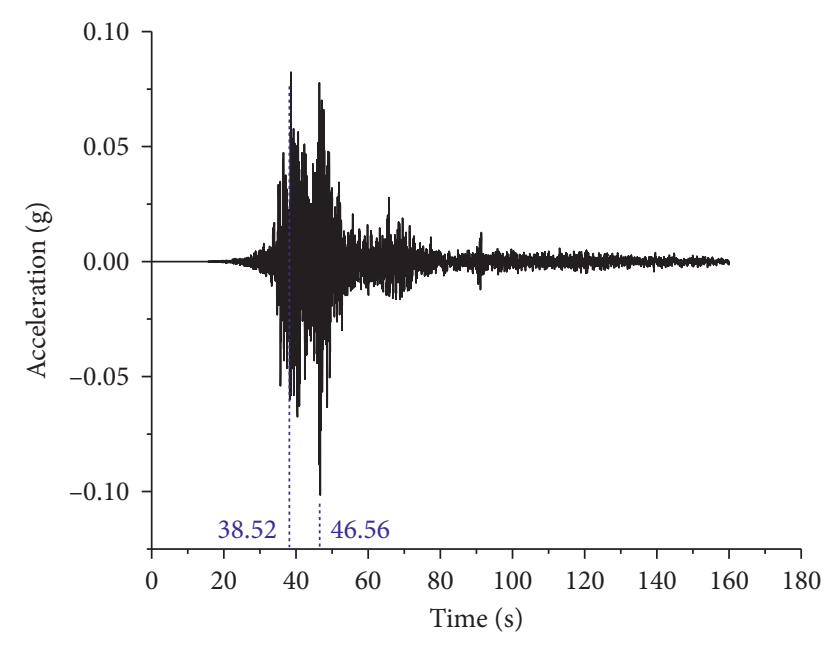

FIgure 7: Acceleration time history curve of WC seismic wave.

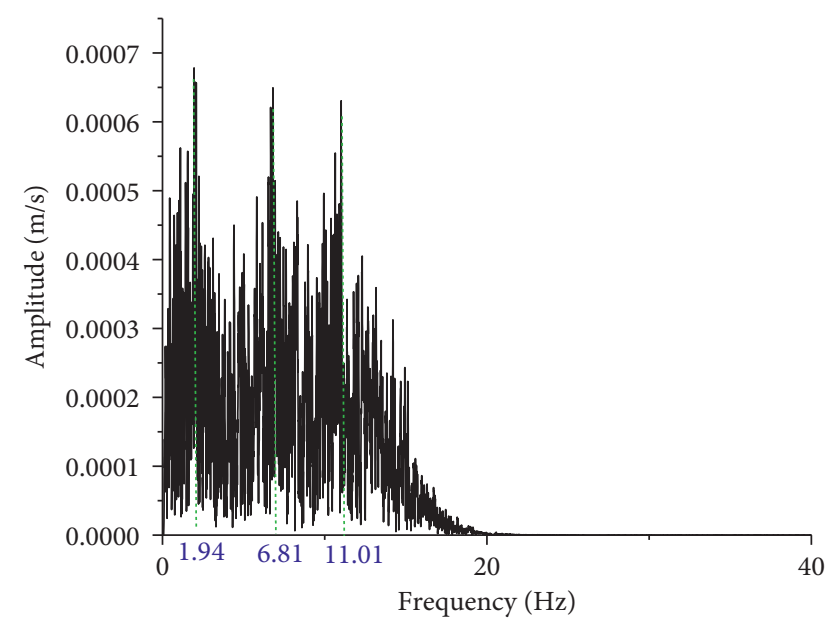

FIgURE 8: Fourier spectrum of WC seismic wave.

between some symmetric points of the left and right holes is obvious. For example, the left hole arch foot (A2) is much larger than the right hole arch foot (A11), and the left hole spandrel (A3) is much smaller than the right hole spandrel (A10). Some symmetrical measuring points have small differences. For example, the acceleration amplification factors of the left and right vaults (A4 and A9) are between 1.5 and 2.5, and the acceleration amplification factors of the two sides of the inverts (A1 and A12) are between 1 and 1.5. The amplification factors of the vault and the invert arch are greater than 1 because the vault is at the horizontal interface between the overlying soil and the underlying gas. The invert is at the horizontal interface between the upper gas and the underlying rock, and the excitation direction of $\mathrm{WC}-\mathrm{Z}$ is its most unfavorable loading direction. The vault is larger than the invert because the upper part of the vault is a rock formation with large gravity, while the upper part of the invert is gas, and the gravity is negligible.

It can be seen from Figure 13 that, under the WC-XZ excitation, the trendency of the vertical acceleration amplification factor of the double-arch tunnel is similar to that under the WC-Z excitation. It shows that the horizontal
TABLE 4: Loading rule of the shaking table test.

\begin{tabular}{lccc}
\hline \multirow{2}{*}{ Number } & Cases & \multicolumn{2}{c}{ Peak acceleration (g) } \\
& & $X$ & $Z$ \\
\hline 1 & WN-1 & - & - \\
2 & WC-X-1 & 0.1 & - \\
3 & WC-Z-1 & - & 0.067 \\
4 & WC-XZ-1 & 0.1 & 0.067 \\
5 & WN-2 & - & - \\
6 & WC-X-2 & 0.2 & - \\
7 & WC-Z-2 & - & 0.133 \\
8 & WC-XZ-2 & 0.2 & 0.133 \\
9 & WN- 3 & - & - \\
10 & WC-X-3 & 0.4 & - \\
11 & WC-Z-3 & - & 0.267 \\
12 & WC-XZ-3 & 0.4 & 0.267 \\
13 & WN- 4 & - & - \\
14 & WC-X-4 & 0.6 & - \\
15 & WC-Z-4 & - & 0.4 \\
16 & WC-XZ-4 & 0.6 & 0.4 \\
\hline
\end{tabular}

excitation has little effect on the overall trend of the vertical acceleration response. As can be seen from Figure 14, the trendency of A1 to A5 is W-shaped, and most of the data are less than zero. The trendency of A8 to A12 is M-shaped (except $0.1 \mathrm{~g}$ ), and most of the data are greater than zero. It shows that the two-way coupled wave increases the vertical acceleration response of some measuring points, but not all measuring points. The vault (A9) and the arch foot (A11) near the slope have a larger amplification factor than the left vault (A4) and the arch foot (A2) of the same height. This is because the measuring points $A 9$ and A11 are close to the slope and are affected by the slope. The effect of increasing the amplification factor of the right hole spandrel (A10) is not obvious (except for $0.1 \mathrm{~g}$ ), indicating that the effect of the slope on the vertical acceleration is also related to the position of the measuring point.

\subsubsection{Acceleration Response Laws under Different Excitation Intensities}

(1) Horizontal Acceleration Response Laws. It can be seen from Figure 15(a) that as the seismic intensity increases, the acceleration amplification factors of the invert of the left hole (A1) and the bottom of the middle wall (A6) are less fluctuating. The trendency of other points under different seismic intensities is obviously fluctuating, and it tends to increase first, then decrease, and then, increase with the increase of seismic intensity.

It can be seen from Figure 15(b) that the trendency of the acceleration amplification factor of the invert of right hole (A12) and the top of the middle wall (A8) is less fluctuating, and the value of the acceleration factor of the arch foot (A11) is less than 1 . The overall trendency is U-shaped. With the increase of seismic intensity, the trendency of the acceleration amplification factors of the left and right holes are obviously fluctuating. It is indicated that the horizontal acceleration amplification factor of each point of the doublearch tunnel is affected by the seismic intensity. 


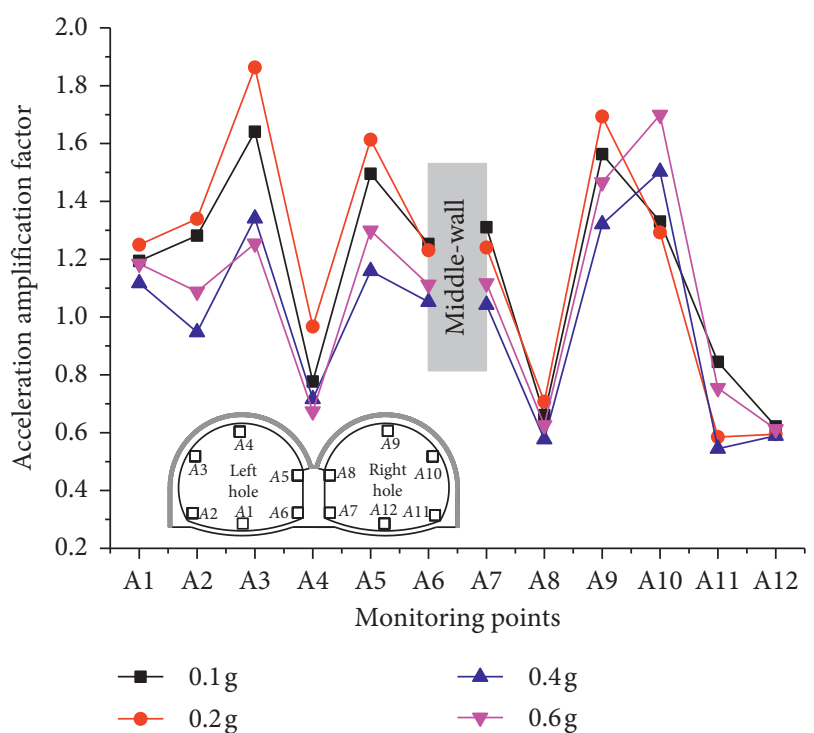

Figure 9: Variation trends of AAF of WC-X in the $X$-direction.

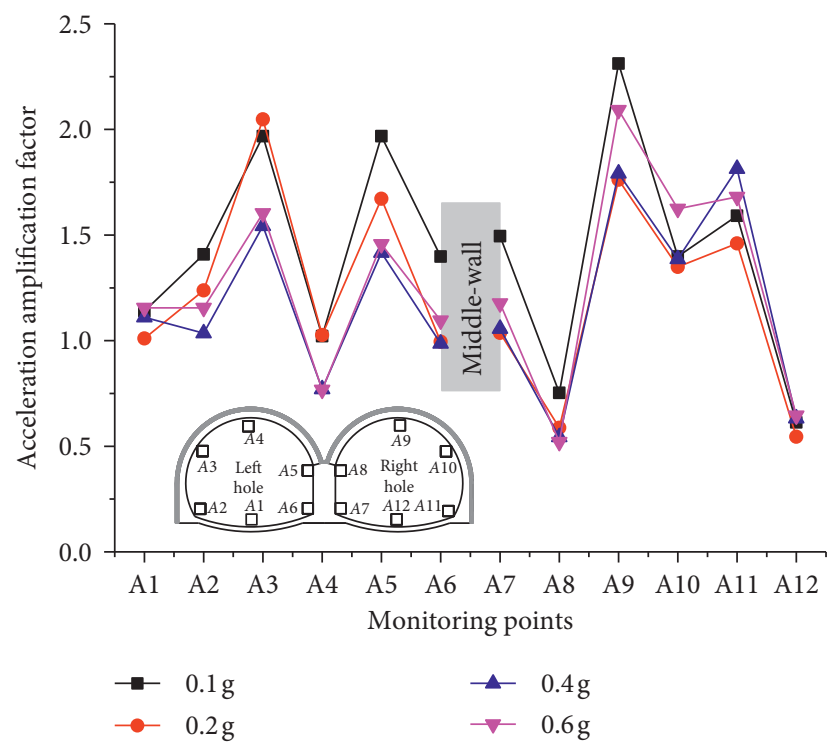

Figure 10: Variation trends of AAF of WC-XZ in the $X$-direction.

The acceleration amplification factors of the left and right holes do not increase with the increase of the excitation intensity; acceleration amplification factor of the left hole at low intensity is larger than that at high intensity. This maybe due to the following reasons: When the seismic wave is at low-intensity excitation, the foam concrete is in the elastic stage, and the damping effect is not obvious. When seismic wave is at the high-intensity excitation, the surrounding rock pressure exceeds the compressive strength of foam concrete, and the resulting plastic deformation can absorb seismic energy. It shows that the effect of foam concrete under the high-intensity seismic wave excitation is better than that under the low-intensity seismic wave excitation.

It can be seen from Figure 16(a) that as the seismic intensity increases, the trend of the spandrel of the left hole

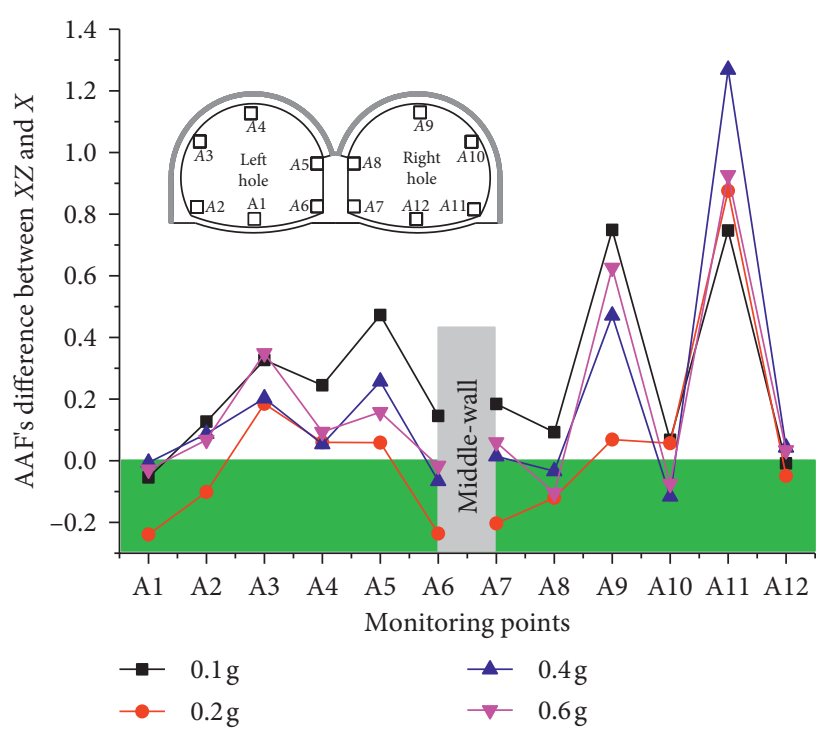

FIGURE 11: The difference between the horizontal AAF of WC-XZ and WC-X.

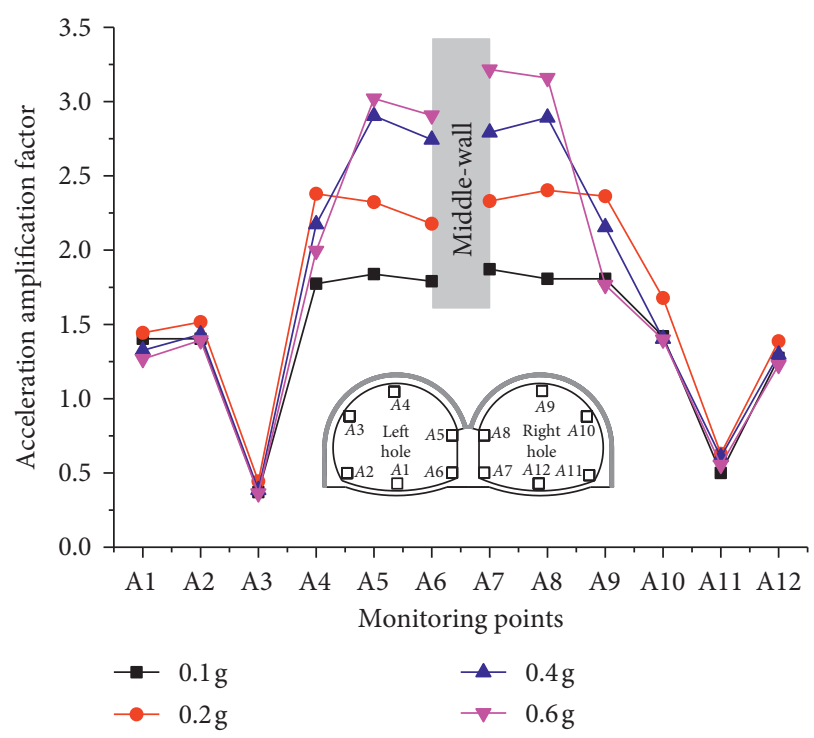

FIgURE 12: Variation trends of AAF of WC-Z in the Z-direction.

(A3) and the vault (A4) will rise first, then decrease and, then, slightly increase. The acceleration amplification factor of the spandrel is the largest in the left hole, and the vault is the smallest in the left hole (except $0.2 \mathrm{~g}$ ). Both the arched foot (A2) and the top of the middle wall (A5) showed a tendency to continue to decline and, then, rise.

It can be seen from Figure 16(b) that the trendency of the acceleration amplification factor of the top of the middle wall (A8) and the invert (A12) of the right hole is relatively flat and less than 1 , and the rest of the measuring points are relatively large. The vault (A9) is U-shaped and has a value greater than 1.6 and a maximum of 2.31 at $0.1 \mathrm{~g}$. It is indicated that, in the right hole, when the WC-XZ is excited, the vault has the largest amplification effect on the horizontal seismic wave. 


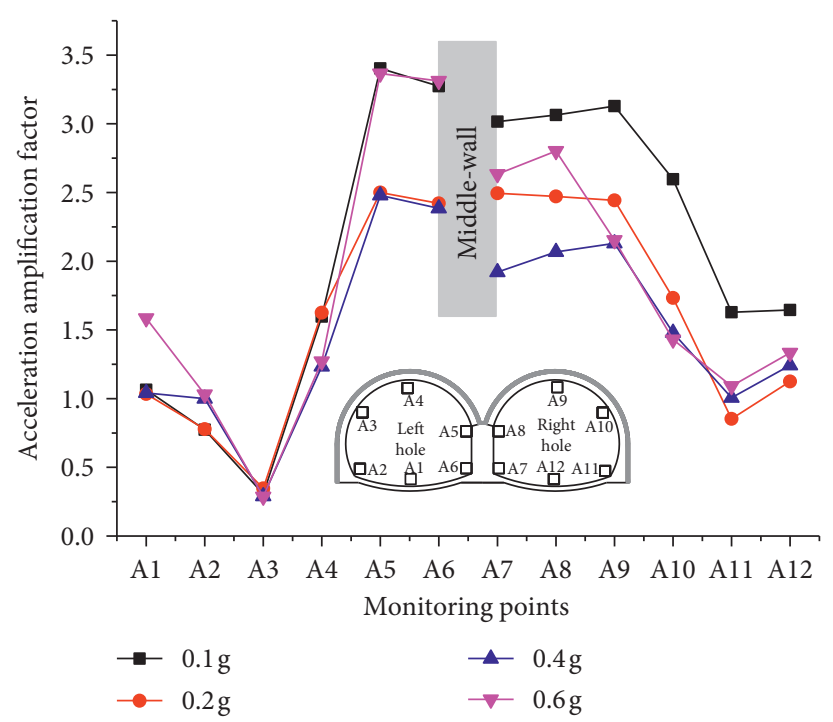

FIgURE 13: Variation trends of AAF of WC-XZ in the $Z$-direction.

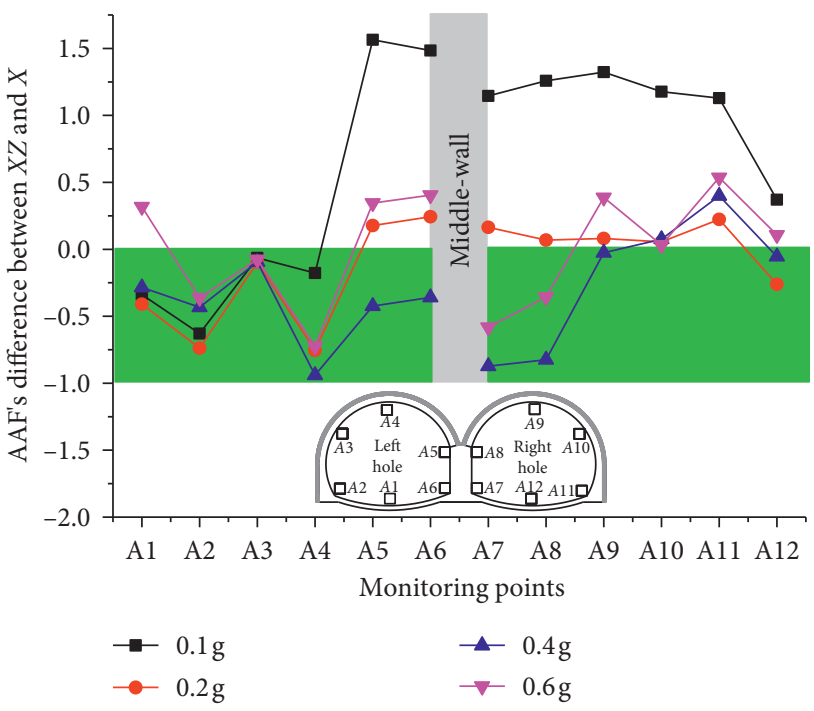

FIgURE 14: The difference between the vertical AAF of WC-XZ and WC-Z.

Under the excitation of WC-XZ, the trendency of the spandrel of the left hole (A3) and the vault (A4) is similar to that of WC-X. It is indicated that the vertical excitation only affects the value of the horizontal acceleration response of these two points and does not affect the variation trend of the amplification factor. The remaining measurement points of the double-arch tunnel are inconsistent with the one-way excitation, indicating that the variation trend of the horizontal acceleration amplification factor of the other measurement points is related to the excitation direction.

(2) Vertical Acceleration Response Laws. It can be seen from Figures 17 (a) and 17(b) that, with the increase of the excitation intensity, both the amplification factors of the left and right sides of the middle wall (A5-A8) increase synchronously with the increase of the excitation intensity. The trendency of the vertical acceleration amplification factors of the left and right vaults all show a trend of increasing first and, then, decreasing, and the rest of the measuring points have smaller fluctuations.

When the WC- $Z$ is excited, the vertical acceleration amplification factor of the middle wall is between 1.5 and 3.5. When the WC-X is excited, the horizontal acceleration amplification factor of the middle wall is between 0.6 and 1.6. When $\mathrm{WC}-\mathrm{Z}$ is excited, the response of the middle wall increases from the low-intensity excitation to high-intensity excitation and is much larger than the response when WC-X is excited. Probably because of the special geometric form of the double-arch tunnel, the vertical damping effect of the foam concrete in the middle wall cannot be fully exerted. The acceleration amplification factor of vault has a downward trend under the high-intensity excitation. It may be because the cutting plane of the foam concrete layer at the vault is orthogonal to the excitation direction. After the surrounding rock pressure reaches the compressive strength of the foam concrete, the energy absorption effect of the foam concrete is better. The other measuring points have different angles due to the direction of excitation and the foam concrete layer, and the foam concrete damping layer exerts different damping effects at other measuring points. Compared with the WC-X excitation, the damping effect of the foam concrete layer is not only related to the position of the measuring point but also related to the direction of the excitation.

It can be seen from Figures 18(a) and 18(b) that, under the excitation of WC-XZ, the vertical acceleration amplification factor of the middle wall of the left hole is much larger than other points, and the overall appearance is U-shaped. The trendency of the spandrel of the left hole (A3) is close to horizontal, and the values are less than 0.5 . It shows that the spandrel of the left hole has a small amplification effect on vertical seismic waves. When WC-XZ is excited, the overall trend of the vertical acceleration amplification factor is similar to that of $\mathrm{WC}-\mathrm{Z}$ one-way excitation, indicating that 


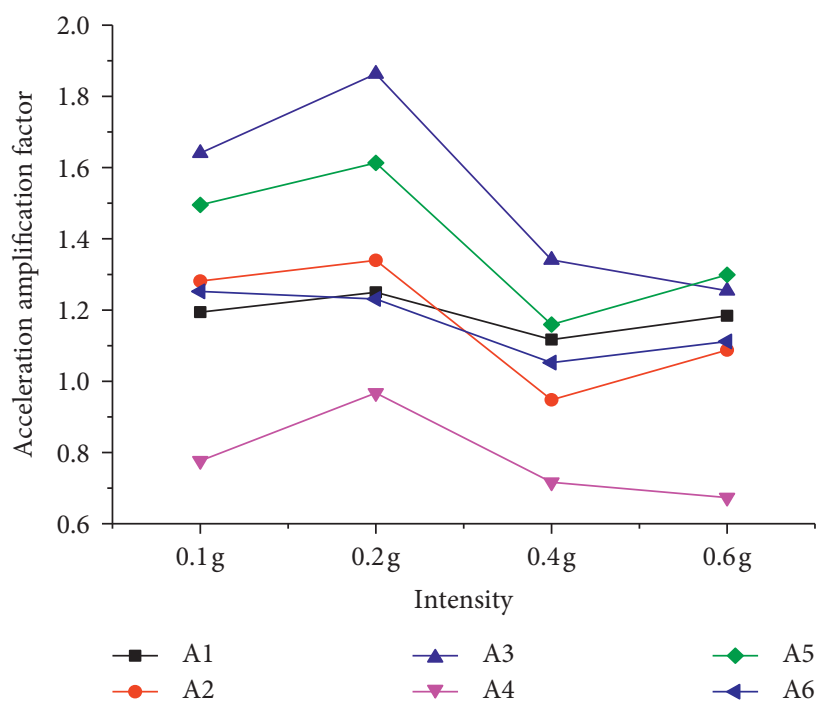

(a)

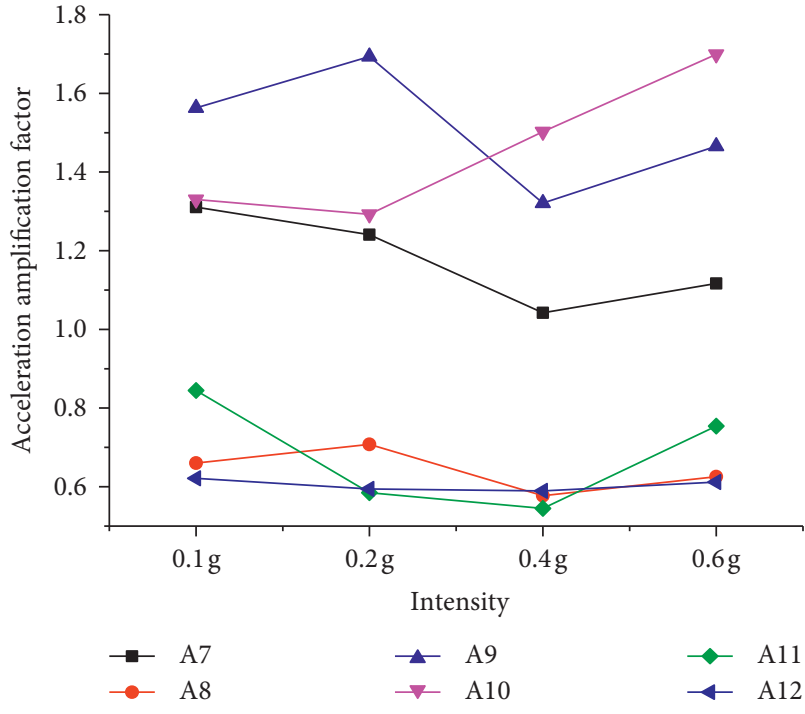

(b)

FIgURE 15: Variation trends of AAF of WC-X in the X-direction at different intensities: (a) left hole and (b) right hole.

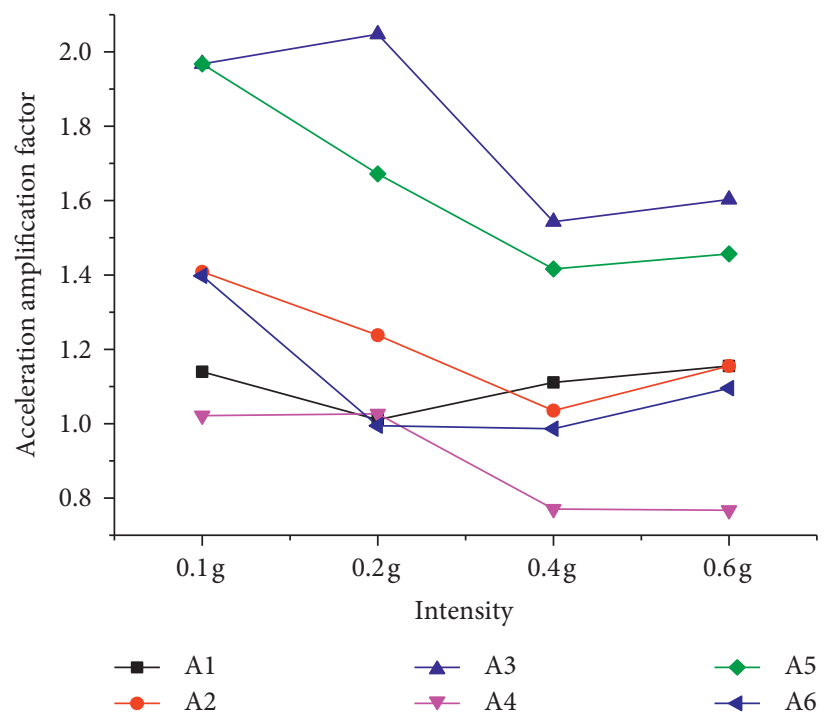

(a)

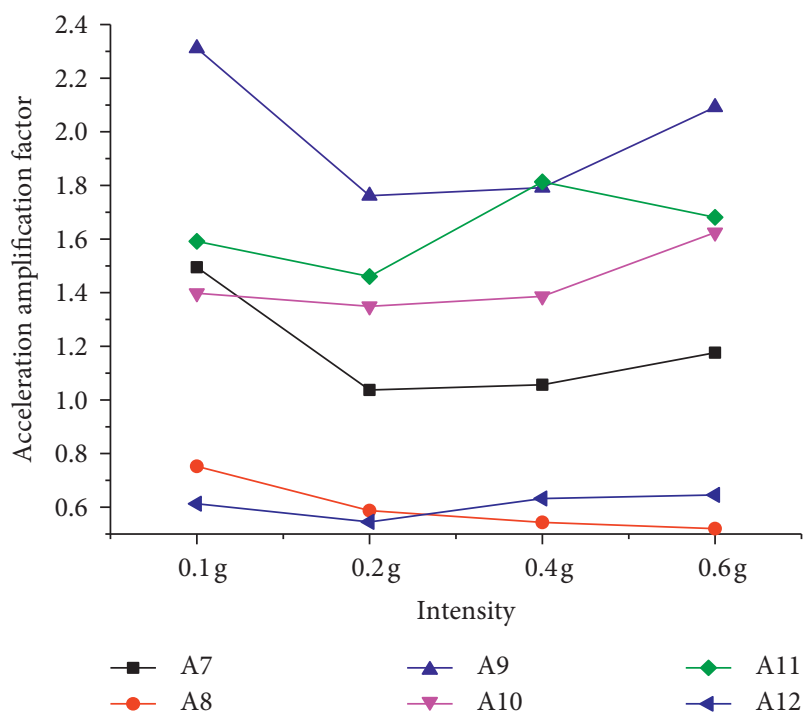

(b)

FIGURE 16: Variation trends of AAF of WC-XZ in the X-direction at different intensities: (a) left hole and (b) right hole.

the horizontal excitation has little effect on the shoulder (A3).

With the increase of the excitation intensity, the acceleration amplification factor trend of the bottom and top of the middle partition wall of the right hole showed a trend of decreasing first and, then, rising. The trend of the vault (A9) and the spandrel (A10) is continuously descending, and the arch foot (A11) and the invert (A12) rise first and, then, rise slowly.

When WC-Z excited, the trendency of the vaults of both holes rises first and, then, decreases continuously. When WC-XZ excited, the vertical acceleration amplification factor of the left vault shows a stepped shape with a horizontal decrease, and the right vault continues to decrease. Compared with the WC-X action, when the WC-XZ excited, the amplification factor of the middle wall and the right-hole measurement point increases significantly at $0.1 \mathrm{~g}$. It shows that the vertical acceleration response of the doublearch tunnel is not only related to the seismic intensity but also related to the direction of excitation.

3.2. Dynamic Strain Response Laws. The test uses a right angle strain rosette as shown in Figure 19 to detect the strain response of the tunnel lining. The tangential direction of the measuring point on the tunnel section is $\varepsilon_{x}$, the radial 


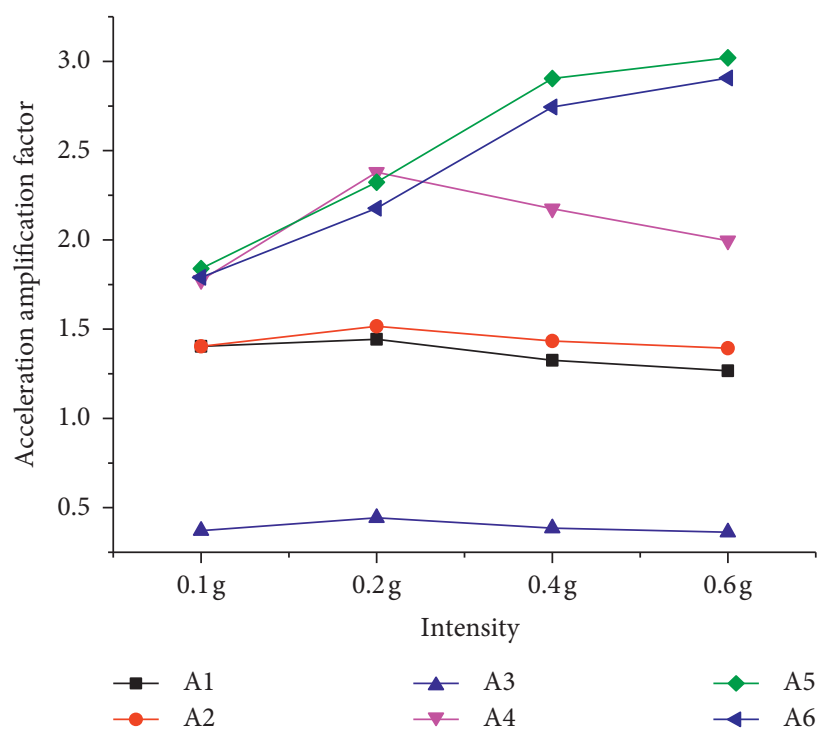

(a)

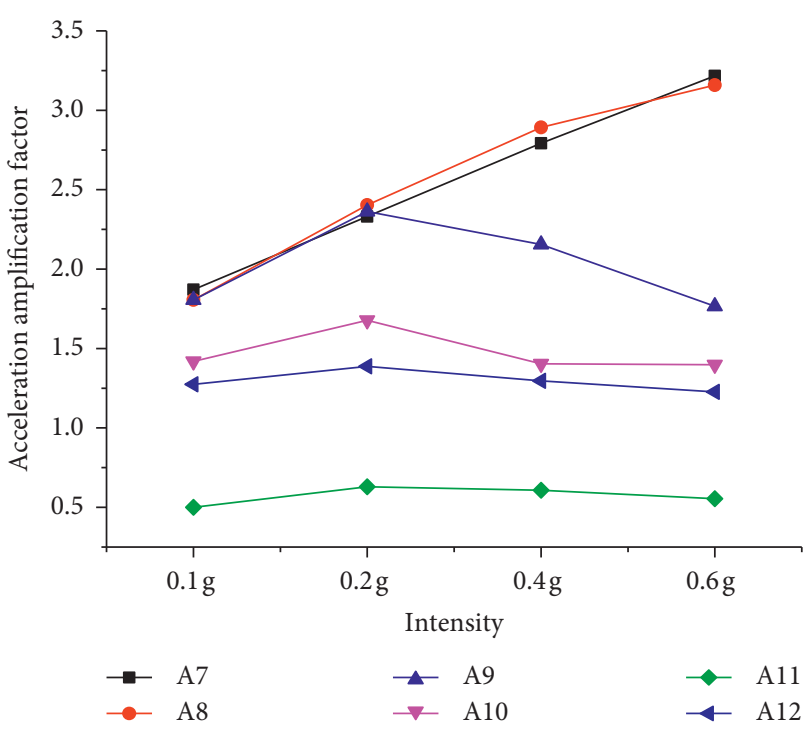

(b)

FIgURE 17: Variation trends of AAF of WC-Z in the Z-direction at different intensities: (a) left hole and (b) right hole.

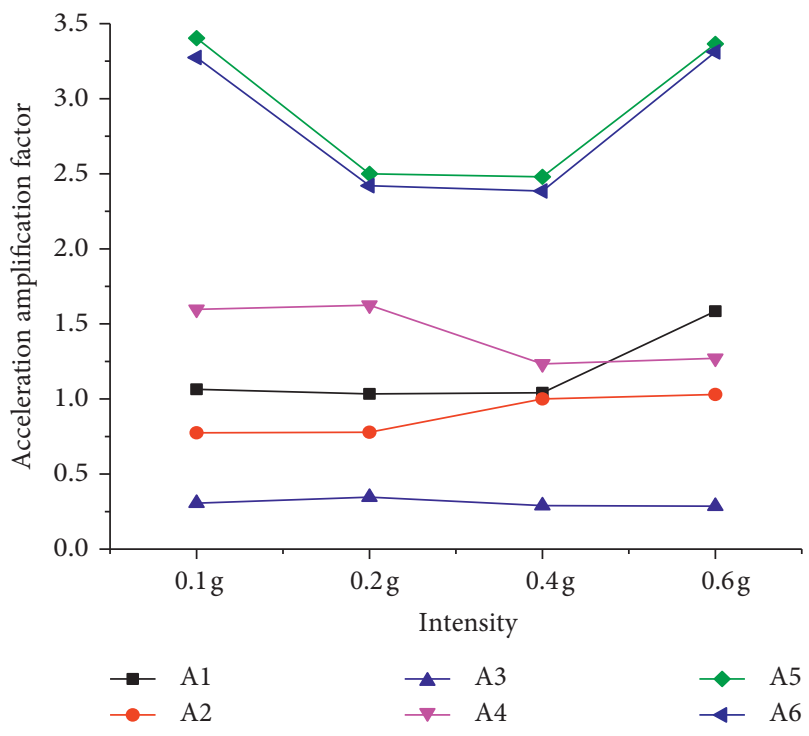

(a)

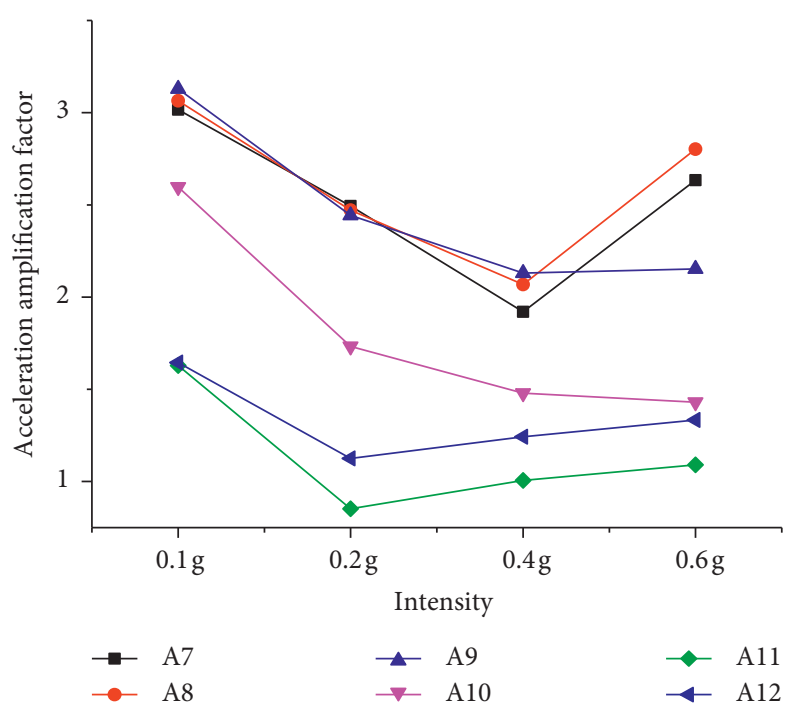

(b)

FIGURE 18: Variation trends of AAF of WC-XZ in the Z-direction at different intensities: (a) left hole and (b) right hole.

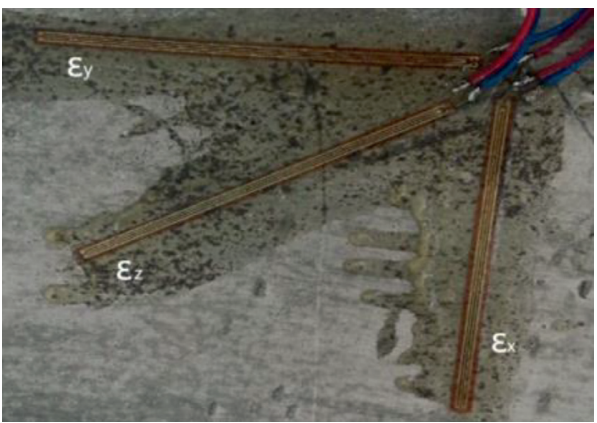

FIGURE 19: Strain rosette. direction of the tunnel is $\varepsilon_{y}$, and the direction of the angle of $45^{\circ}$ is $\varepsilon_{z}$. $e$ indicates the strain, and $\mu \varepsilon$ denotes the microstrain, namely, $\mu \varepsilon=10^{-3} \varepsilon$. The strain peak is calculated using the following formula:

$$
\begin{aligned}
& \varepsilon_{\text {Max }}=\frac{1}{2}\left(\varepsilon_{x}+\varepsilon_{y}\right)+\frac{\sqrt{2}}{2} \sqrt{\left(\varepsilon_{x}-\varepsilon_{45^{\circ}}\right)^{2}+\left(\varepsilon_{45^{\circ}}-\varepsilon_{y}\right)^{2}}, \\
& \varepsilon_{\text {Min }}=\frac{1}{2}\left(\varepsilon_{x}+\varepsilon_{y}\right)-\frac{\sqrt{2}}{2} \sqrt{\left(\varepsilon_{x}-\varepsilon_{45^{\circ}}\right)^{2}+\left(\varepsilon_{45^{\circ}}-\varepsilon_{y}\right)^{2}} .
\end{aligned}
$$

Figures 20(a), 20(b), and 20(c) represent the graphs showing the strain time history of the arch foot of the left 


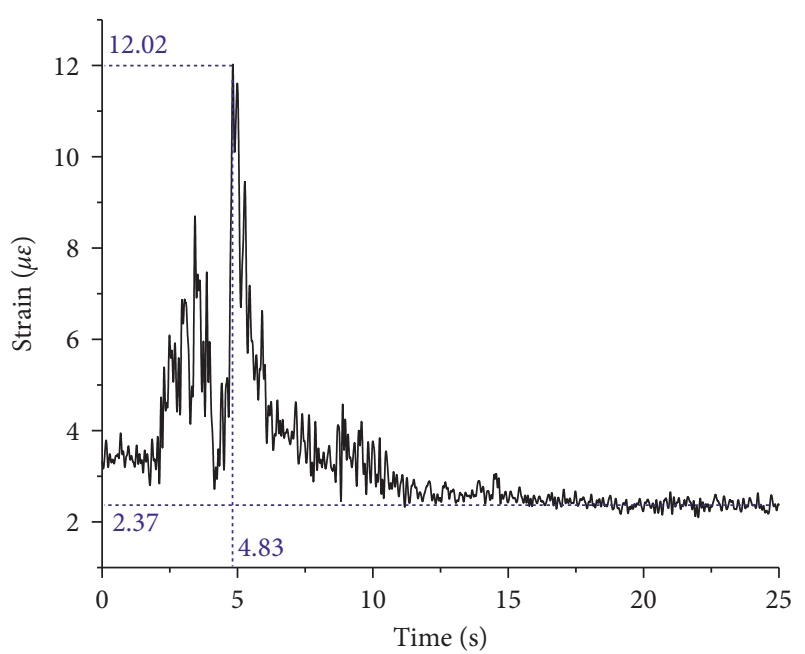

(a)

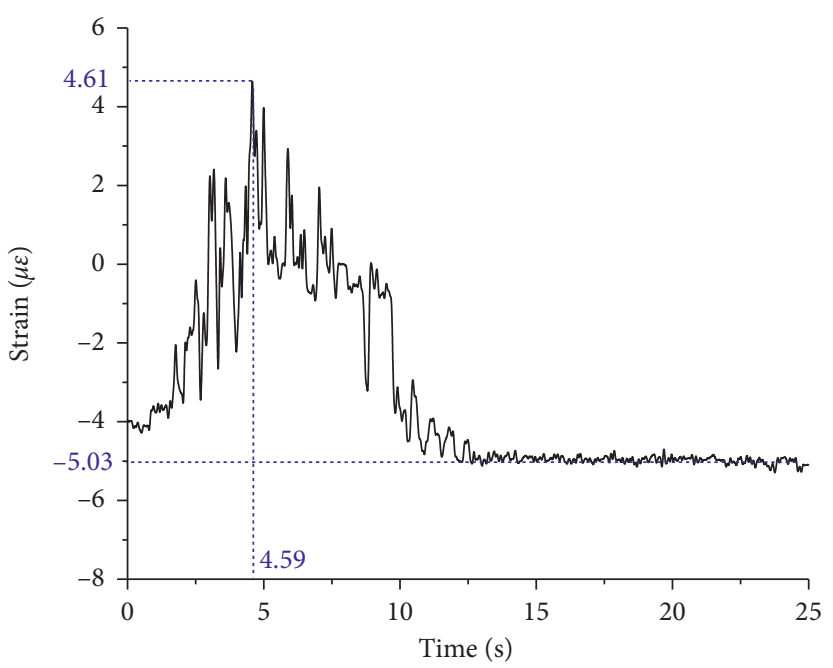

(b)

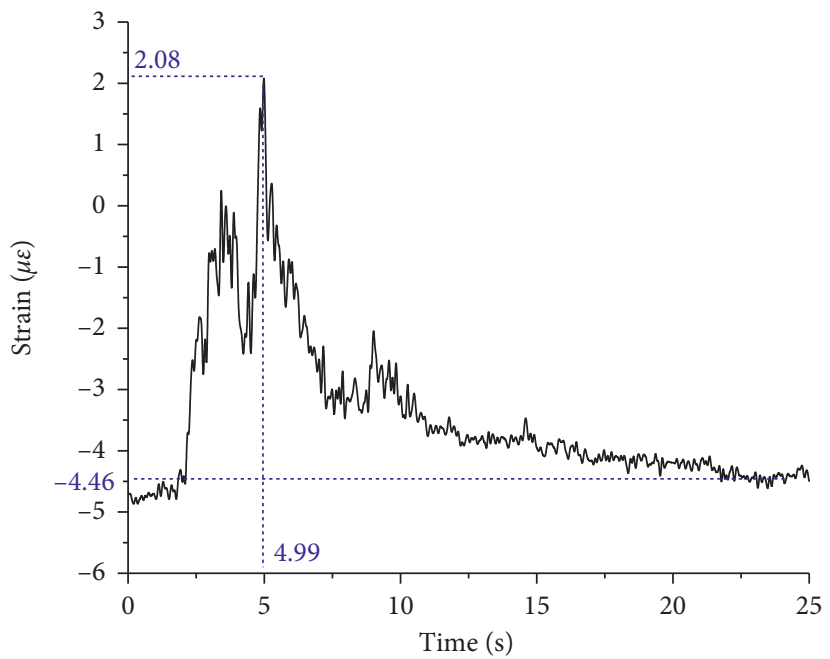

(c)

Figure 20: Time history curves of strain at the left hole arch foot: (a) $X$-direction strain $\left(\varepsilon_{x}\right)$, (b) $Y$-direction strain $\left(\varepsilon_{y}\right)$, and (c) $Z$-direction strain $\left(\varepsilon_{45^{\circ}}\right)$.

hole (S2) when excited by $0.6 \mathrm{~g}$-WC-X. In the figure, the strain of three directions did not start from 0 . This is because when the test was carried out to $0.6 \mathrm{~g}$, the structure had residual deformation in the previous working conditions, and the damage was accumulated to varying degrees. The residual strain in the $\varepsilon_{x}$-direction is a tensile strain greater than 0 , and the other two directions are compressive strains less than zero. After the end of the working condition, it did not return to the starting line, indicating that, after this working condition, the structure produced irreversible plastic deformation again.

It can be seen from Figures 21(a), 21(b), 21(c), and 21(d) that the trendency of the large principal strain and the small principal strain of the double-arch tunnel has a certain symmetry about the 0 -axis, and the large principal strain is larger than the small principal strain. Such as, under the excited of WC-X at $0.2 \mathrm{~g}$, the large principal strain at the top of the wall (S7) in the left hole is 1.7 times that of the small principal strain. The large main strain at the top of the middle wall (S10) of the right hole is 1.8 times that of the small principal strain. It shows that the double-arch tunnel is mainly subjected to tensile stress. The point of maximum stress is the top of the left hole (S7), and the invert (S1) and the vault (S4) of the left hole are also larger. The dynamic strain of each measuring point of the double-arch tunnel increases with the increase of the excitation intensity, and the increasing amplitude of the large principal strain is higher than the small principal strain. For example, under the action of WC-XZ, the left hole invert (S1) increases 5.5 times from $0.1 \mathrm{~g}$ to $0.2 \mathrm{~g}$, and the small principal stress increases 1.2 times.

The left hole strain is larger than the right hole strain, and as the excitation intensity increases, the difference between the left and right strains increases. It shows that the greater the excitation intensity, the more uneven the force on the cross section of the tunnel, the greater the probability of 


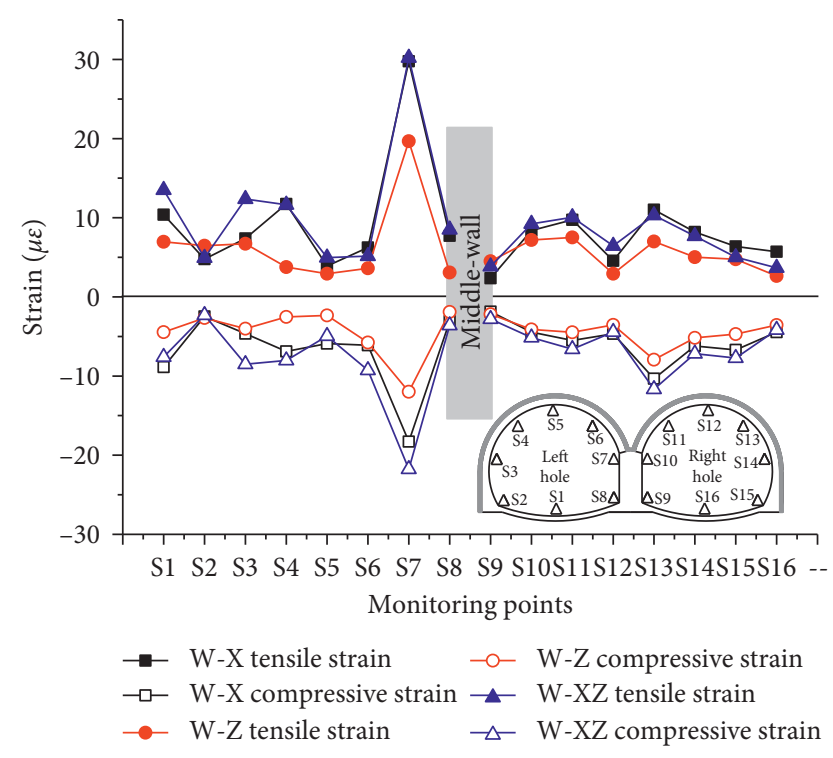

(a)

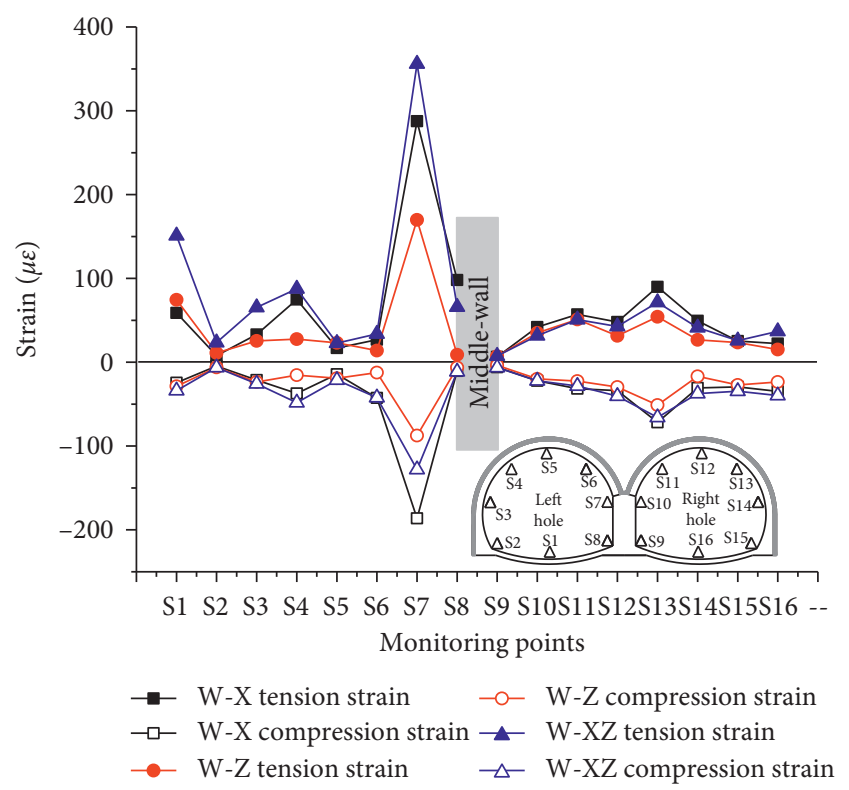

(c)

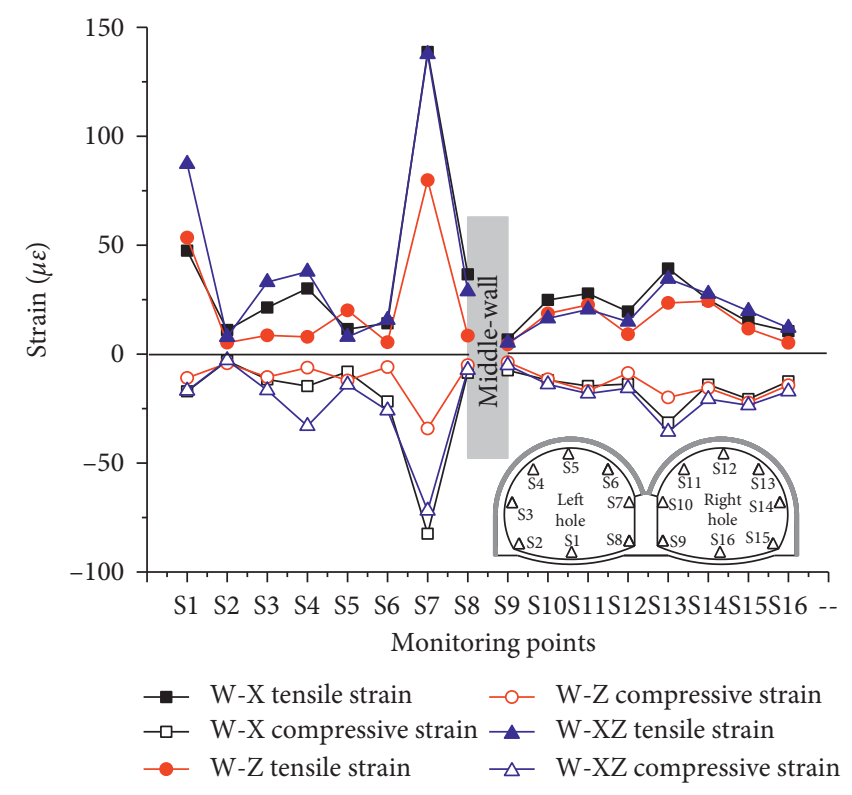

(b)

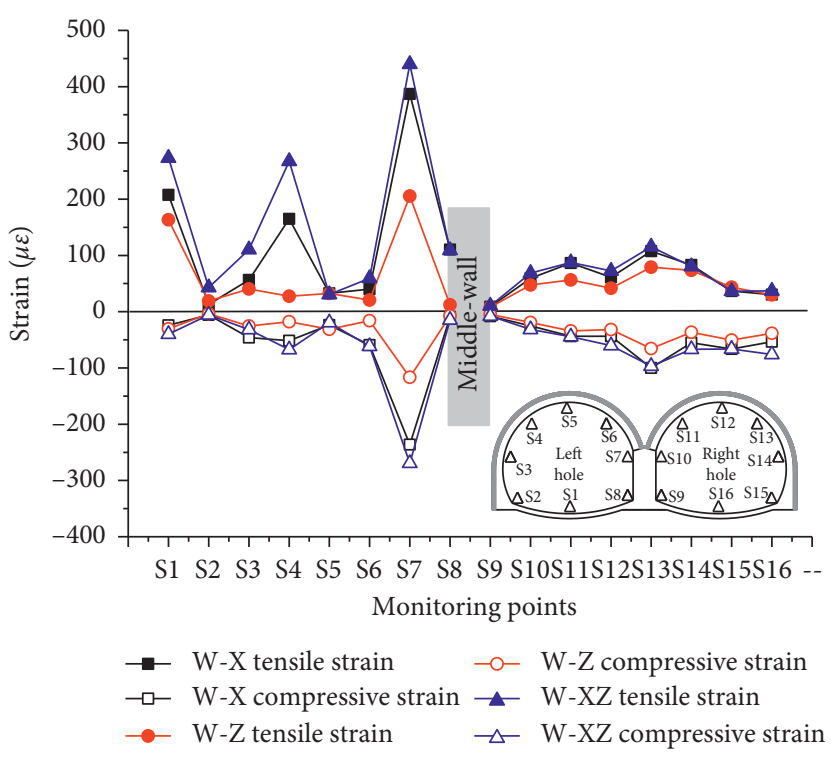

(d)

FIgURE 21: Variation trends of the peak strain: (a) $0.1 \mathrm{~g}$, (b) $0.2 \mathrm{~g}$, (c) $0.4 \mathrm{~g}$, and (d) $0.6 \mathrm{~g}$.

cracking, and the more susceptible the structure is to shear failure. In the three directions of excitation, the double-arch tunnel strain is the largest when WC-XZ is excited, and the $\mathrm{WC}-\mathrm{Z}$ is the smallest. It shows that the horizontal incentive response has a greater impact. The strain trendency of the right hole shows an "M" shape (S9 S15), and the shape does not change significantly with the increase of the excitation intensity.

3.3. Cracks Distribution Laws. Figure 22(a) is a physical picture of foam concrete cracking attached to the outer surface of the lining. As mentioned earlier, the lining is subjected to both tensile and compressive stresses. Foamed concrete has low tensile strength and produces more cracks. The crack along the $Y$-direction is the largest, indicating that the horizontal $X$-direction tensile stress is the largest. There are many secondary cracks in the remaining directions, and the direction is uncertain. Except for the labels in the figure, the capillary cracks on the surface of the entire foam concrete layer are numerous and miscellaneous. It is indicated that the stresses are different in size and direction in the contact surface between the surrounding rock and the foam concrete.

Figure 22(b) is a physical picture of the crack of the inner surface lining of the left hole. In the left hole, the top of the 


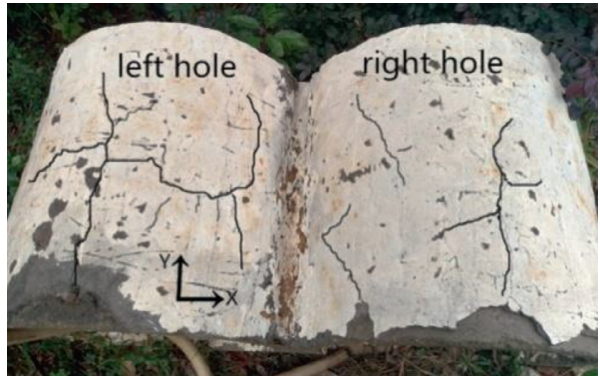

(a)

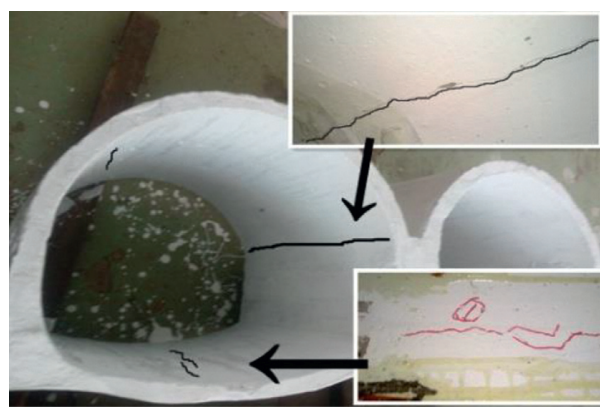

(b)

Figure 22: Cracks in the lining.

middle wall shows a through crack, and the spandrel and the invert crack have not yet penetrated. It shows that the top of the middle wall in the left hole is the most damaged, while the invert and the spandrel are the second.

\section{Conclusions}

(1) The left hole is uniformly covered with soil, and the trendency of the curve line (A2 A6) of the horizontal acceleration amplification factor shows a relatively regular $\mathrm{M}$-shape. The right hole is affected by the uneven soil and the superimposed wave field generated by the slope surface, and the acceleration response has no symmetry.

(2) The damping effect of foam concrete in high intensity is better than that in low intensity, and the damping effect of foam concrete is related to the excitation direction and the position of the measuring point. On the same horizontal plane, with the vertical centerline of the middle wall as the axis of symmetry, the horizontal acceleration response of the left and right symmetrical points is quite different. The vertical acceleration is different between the arch foot and the spandrel, and the difference of other points is relatively small.

(3) The slope has a significant impact on the right hole, mainly in (1) uneven distribution of Earth pressure caused by uneven soil covering; (2) the superimposed wave field caused by the reflection of seismic waves on the slope. When WC-XZ is excited, the influence of slope on lining is more complicated than WC-X and WC-Z.

(4) Under the excitation of WC-X and WC-Z, the variation trend of the acceleration amplification factor is quite different. It shows that the acceleration response of the double-arch tunnel is greatly affected by the incident direction of the seismic wave. Under the excitation of seismic waves in the same direction, the strain increases with the increase of seismic intensity, indicating that the strain is greatly affected by the seismic intensity.

(5) According to the law of acceleration response, strain response, and crack, at the top of the middle wall of the left hole, severe stress concentration occurs and a through crack occurs. It shows that the overall seismic performance of the double-arch tunnel is poor. In the middle wall, the spandrel and the vault of the left hole and the spandrel, vault, and arch foot of the right hole are weak parts of the earthquake resistance, and special attention should be paid to the seismic design.

\section{Data Availability}

The data used to support the findings of this study are included in the article.

\section{Conflicts of Interest}

The authors declare no conflicts of interest.

\section{Acknowledgments}

This work was supported by the National Natural Science Foundation of China (grant nos. 51204125 and 51404309) and the Hunan Provincial Natural Science Foundation (grant nos. 2018JJ3882 and 2020JJ4944).

\section{References}

[1] J. Lai, H. Fan, B. Liu, and T. Liu, "Analysis of seismic response of shallow large section multi-arch tunnel," Procedia Engineering, vol. 15, pp. 5473-5477, 2011.

[2] X. Yang, "Dynamic constructional response of a shallowburied and unsymmetrical-loaded double-arch tunnel across an ancient landslide," Journal of Engineering Geology, vol. 14, no. 3, pp. 314-319, 2006.

[3] Y. Ling, "Dynamic seismic responses of a double-arch tunnel in high-intensity earthquake region," Modern Tunnelling Technology, vol. 45, no. 6, pp. 11-15, 2011.

[4] X. L. Yang, B. Q. Zhang, Z. B. Wang, J. F. Zou, and L. Li, "Earthquake response of large span and double-arch shallow tunnel," Journal of Central South University, vol. 37, no. 5, pp. 991-996, 2006.

[5] Z. Z. Wang, Z. S. Wang, and B. Gao, "Research on seismic measures of double-arch tunnel portals in high-intensity earthquake zone," China Journal of Highway \& Transport, vol. 24, no. 6, pp. 80-85, 2011.

[6] T. Lianjin, H. Sen, Z. Xu et al., "Large-scale shaking table test for dynamic response in portal section of mountain tunnel 
with different gradients of upward slope," Rock and Soil Mechanics, vol. 35, no. 1, pp. 91-98, 2014.

[7] H. Yu, Y. Yuan, G. Xu, Q. Su, X. Yan, and C. Li, "Multi-point shaking table test for long tunnels subjected to non-uniform seismic loadings-part II: application to the HZM immersed tunnel," Soil Dynamics and Earthquake Engineering, vol. 108, pp. 187-195, 2018.

[8] X. Jiang, F. Wang, H. Yang, G. Sun, and J. Niu, "Dynamic response of shallow-buried small spacing tunnel with asymmetrical pressure: shaking table testing and numerical simulation," Geotechnical and Geological Engineering, vol. 36, no. 4, pp. 2037-2055, 2018.

[9] X. L. Jiang, F. F. Wang, H. Yang et al., "Dynamic response of shallow-buried tunnels underAsymmetrical pressure distributions," Journal of Testing and Evaluation, vol. 46, no. 4, pp. 1574-1590, 2018.

[10] F. Wang, X. Jiang, and J. Niu, "The large-scale shaking table model test of the shallow-bias tunnel with a small clear distance," Geotechnical and Geological Engineering, vol. 35, no. 3, pp. 1093-1110, 2017.

[11] G. Zhenchang, X. Qiu, and D. Tao, "Seismic responses of large section tunnel with shallow coverand unsymmetrical loading," Journal of Natural Disasters, vol. 27, no. 3, pp. 68-76, 2017.

[12] W. Shuaishuai, G. Bo, Z. Yu, and M. Ma, "Shaking table test on tunnel front slope with weak intercalation," Chinese Journal of Rock Mechanics and Engineering, vol. 34, no. s1, pp. 2699-2705, 2015.

[13] D. Wang, J. Yuan, Y. Zhu, and G. Cui, "Mechanism of seismic damage and mode test on absorpti -on joint damping technology of tunnel across junction of soft and hard rock in highly seismic area," Chinese Journal of Rock Mechanics \& Engineering, vol. 36, pp. 4113-4121, 2017.

[14] G. Ping, J. Tang, Q. Quan, C. He, and Q. Yan, "Shaking table test for tunnel with shock absorption layer though fault zone," Journal of Central South University, vol. 44, no. 6, pp. 25202526, 2013.

[15] G. Ping, W. Chuan, T. Jinliang, and L. Lin, "Analysis of dynamic response properties for tunnl through fault fracture zone," Chinese Journal of Rock Mechanics and Engineering, vol. 31, no. 7, pp. 1406-1413, 2012.

[16] M. Hajialilue-Bonab, M. Farrin, and M. Movasat, "Shaking table test to evaluate the effects of earthquake on internal force of Tabriz subway tunnel (line 2)," Physical Modelling in Geotechnics, vol. 2, no. 7, pp. 797-801, 2018.

[17] H. Fuyama, Y. Chiaki, S. Kajii, and M. Sakuno, "Computation of input energy to test structure on shaking table test," in Proceedings of the Seismic Engineering, Volume 2, pp. 1-6, San Diego, CA, USA, August 2004.

[18] S. Furukawa, E. Sato, Y. Shi, T. Becker, and M. Nakashima, "Full-scaleshaking table test of a base-isolated medical facility subjected to vertical motions," EarthquakeEngineering \& Structural Dynamics, vol. 42, no. 13, p. 1931, 1949.

[19] P. J. Meymand, Shaking Table Scale Modeltests of Nonlinearsoil-Pile-Superstructur Interactionin Soft Clay, University of California, Berkeley, CA, USA, 1998.

[20] S. Iai, "Similitude for shaking table tests on soil-structure-fluid model in $1 \mathrm{~g}$ gravitational field," Soils and Foundations, vol. 29, no. 1, pp. 105-118, 1989.

[21] X. Bing-Wei and J. Xin-Liang, "Soil chamber design of shaking test table for large-scale soil-pile-complex structure interaction," Journal of Tianjin University, vol. 43, no. 10, pp. 912-918, 2010.
[22] D. Lombardi, S. Bhattacharya, F. Scarpa, and M. Bianchi, "Dynamic response of a geotechnical rigid model container with absorbing boundaries," Soil Dynamics and Earthquake Engineering, vol. 69, no. 1, pp. 46-56, 2015.

[23] S. Xie, H. Lin, Y. Chen, R. Yong, W. Xiong, and S. Du, “A damage constitutive model for shear behavior of joints based on determination of the yield point," International Journal of Rock Mechanics and Mining Sciences, vol. 128, pp. 1-12, 2020.

[24] S. Xie, H. Lin, Y. Wang et al., "A statistical damage constitutive model considering whole joint shear deformation," International Journal of Damage Mechanics, vol. 29, no. 6, pp. 1-21, 2020.

[25] Y. Wang, H. Zhang, H. Lin, Y. Zhao, and Y. Liu, "Fracture behaviour of central-flawed rock plate under uniaxial compression," Theoretical and Applied Fracture Mechanics, vol. 106, pp. 1-15, 2020. 